" perturbative function," and gives the elements, step by step, for the determination of the orbit of (334).

Absorption in the Solar Atmosphere.-In an article published in No. 2, vol. xix., of the Astrophysical Journal, Mr. Frank W. Very discusses the cause which produces the apparent selective absorption of the more refrangible radiations emitted by the photosphere which takes place in the solar atmosphere. He points out that beyond certain $1 \mathrm{kmits}$ the increased depth of an "emission" layer does not increase the radiating power owing to the fact that beyond these limits the increased emission is counterbalanced by the increased absorption in the outer layers; similarly the line absorption produced by a gas does not increase indefinitely with the depth. For this reason he believes that the absorbing atmosphere is everywhere deeper than is actually essential to produce the absorption observed, and consequently it makes little or no difference whether the emission and absorption take place at the centre or the edge of the solar disc. Mr. Very contends that the apparent selective absorption is due to "selective scattering" rather than to "absorption," the more refrangible radiations being scattered and reflected by the small particles which float about in the solar atmosphere; further, he thinks that the scattering does not take place solely in a thin layer immediately above the photosphere, but is active even in the !imits of the outer corona. Whereas " absorption "would require that the absorbing, medium should become heater "selective scattering", does not, for the radiations are simply refleeted.

This theory explains the nearly constant radiations of sun-spots when nearing the limb by supposing that spots, being cooler than the photosphere, only emit, at any time, the less refrangible radiations which are not affected by the extremely fine particles that cause the scattering.

Wave-Length of the Green Cadmivm Line.-It has been noticed by many spectroscopists who are interested in the determination of absolute wave-lengths that the wave-length of the green cadmium line at $\lambda 5^{086}$ as determined by $M$. Hamy (Comptes rendus, No. 130, p. 490, 1900) differs considerably from the value obtained for the same line by MM. Michelson and Benoit. This discrepancy is now accounted for by M. Ch. Fabry, who shows that under the conditions obtained by Michelson in a tube of cadmium vapour with electrodes the line is a close doublet, whereas in the tube used by Hamy without electrodes it is a triplet, and the latter observer measured the less refrangible component which does not appear under the former conditions. M. Fabry has determined the interval between the component measured by Michelson and the extra line measured by Hamy, and has found that on taking the value of this interval into account the apparent discrepancy is reduced from $I_{5}$ in $1,000,000$ to 3 in $10,000,000$ (Astrophysical Journal, No. 2, vol. xix.).

A Bright Meteor.-Mr. Roland Mott writes to say that on March 22 he observed a bright meteor from a position four miles west of Gloucester. "The meteor was in the north-eastern sky, and first appeared at an altitude of about 45 degrees from the horizon, falling directly towards the earth. It had the appearance of a brilliant arc lamp, and far outshone the stars of the Great Bear, although they and the moon were very bright. The time was 9.58 p.m."

Spectra of Mixed Gases.--From a number of experiments made in order to ascertain the reason of the predominance of one spectrum over another in a mixture of gases, Mr. P. C. Nutting, of the National Bureau of Standards, Washington, has arrived at the definite conclusion that at st ch low pressures (O.I to to $\mathrm{mm}$.) as obtain in a Plücker tube, and under a homogeneous excitation of not more than ro milliamperes, "the spectrum of a gas of greater atomi : weight will be the brighter."

During his experiments he has. found that neither the relative quantities nor the metallic or non-metallic character of the vapours present affect this result. The introduction of one molecule of mercury into three thousand molecules of hydrogen will reduce the brightness of the hydrogen spectrum at least one half, and sulphur and iodine (nonmetals) are nearly as effective in causing this reduction as is mercury.

About eighty combinations of the fifteen readily vapour- isable elements have been studied, and it is hoped to extend the results by using quartz tubes in which even copper and silver may be vapourised.

In concluding his communication $\mathrm{Mr}$. Nutting discusses the effects of chemical combination on these results, and the explanation of the latter afforded by the modern electron theory (Astrophysical Journal, No. 2, vol. xix.).

\section{RETURN OF THE NATIONAL ANTARCTIC EXPEDITION.}

THE Discovery, with the members of the National Antarctic Expedition on board, arrived at Lyttelton, New Zealand, on April I, accompanied by the relief ships Morning and Terra Nova. The news of the safe return of the expedition has been received with satisfaction; and there is every reason to believe that the scientific results obtained will make the expedition a noteworthy one in the records of polar exploration.

The Discovery left England in the summer of $190 \mathrm{r}$ and reached Lyttelton on November 23 of that year. A few weeks later the vessel sailed for the Antarctic, and the first news of the work accomplished was brought back by the relief vessel Morning in March of last year (NATURE, vol: 1xvii. p. 5I6). It was evident from the information then received that the expedition had already achieved great success both as regards exploration and scientific observation, but some anxiety was felt as to the chances of the Discovery being released from the ice during the southern summer just passed. When the winter quarters of the Discovery were found, the ice prevented the Morning from approaching the vessel to a less distance than eight miles and the transfer of coal and provisions had to be done by means of sledges. As the Discovery only had provisions to last until January of this year, it was considered necessary to send out two vessels to relieve the expedition and bring back the members if the ship could not get free. The Morning and Terra Nova were therefore equipped for this purpose, and sailed from Hobart on December 5, 1903, and reached the edge of the ice on January 5 of this year. There were then seventeen miles of ice between the Discovery and the sea, but heavy weather and explosives assisted this to break up, and in the middle of February the vessel was in open water.

Commander Scott's report upon the results of the first year's work in the Antarctic was summarised in Naturi of July 30, I903 (vol. 1xviii. p. 307); but some additional details of interest are given in Press messages from New Zealand. A Reuter message states that the interior of Victoria Land is found to rise to a height of 9000 feet, and is evidently a vast continental plateau.

Wilkes Land was found to be non-existent, the Discovery sailing over the region. where it has been charted. Since Ross's time, the ice is alleged to have broken back 30 miles from the barrier, which is moving northward at the rate of a quarter of a mile a year.

The main practical interest of the expedition lies in the results of the magnetic investigations. Continuous observations were taken in the neighbourhood of the magnetic Pole.

One primitive form of insect life was secured, and much information obtained as to the higher forms of animal life. The latter consisted mostly of birds, including the emperor penguin, specimens of which have not previously been found in these regions. The only species of living plants secured were mosses and lichens, but sandstone fossil remains of dicotyledonous plants from an altitude of 8000 feet were obtained on a sledging trip westward.

The following particulars of the expedition are from an interview which the correspondent of the Daily Mail at Christchurch, New Zealand, had with Commander Scott, published in that journal on Saturday last.

All went well after the departure of the Morning in 1903 . The ice renlained fast and firm within four miles of the Discovery. The weather was colder but less windy than in 1902 . One hundred degrees of frost were recorded in May. The routine of scientific work and observations continued as in the previous year.

Sledging opened in September under the most severe conditions. Orie party made a depöt to the south; another 
party visited Emperor and Penguin Islands and surveyed Cape Crozier with complete success. The temperatures encountered by the parties were constantly below 50 degrees and frequently below 60 degrees. The lowest recorded was 68 degrees. A third party found a new route to the west and established a depot 2000 feet up the glacier, sixty miles from the ship.

On October 6 a party started for the strait in latitude 80 degrees south. The strait was found to contain a large glacier formed from the inland ice. Detailed information was obtained as to the exact point of junction between the barrier ice and the land, and a depot established last year was found to have moved a quarter of a mile to the north. The party returned on December I3.

A party. started on November Io, with five weeks' provisions, and reached a point 160 geographical miles southeast of the ship, travelling continuously over a level plain. No trace of land and no obstacles in the ice were encountered, and evidence was obtained showing this vast plain to be afloat. A most uniform series of magnetic observations was secured.

A party set out to the west on October 12, and reached a height of 5000 feet on the glacier, 80 miles from the ship, on October 18 . The ship was reached again on October 21 , and on October 26 another start was made. The party gained the summit on November II, and crossed 180 degrees, the magnetic meridian, on November 20 in about longitude $155^{\frac{1}{2}}$ degrees east.

Commander Scott proceeded west with two men for eight and a half days, and reached a point 270 miles from the ship in latitude 78 degrees south and longitude $146 \frac{1}{2}$ degrees east. He regained the glacier on December I4, and reached the ship on Christmas Eve.

The interior of Victoria Land stretches continuously at a height of 9000 feet. It is evidently a vast continental plateau. No land was visible after losing sight of the ranges which front the coast. The temperatures were low and the wind increasingly strong. The glacier valley affords magnificent scenery and gives a natural geological section of the mountains. Mr. Ferrar and two men accompanied Commander Scott to the summit, and on the return journey they explored the valley in detail and discovered sandstone with plant remains.

In the middle of December a camp was formed eight miles north of the ship; and all hands were set to work on icesaws in the rieighbourhood to cut. a passage out. Commander Scott arrived at the camp on December 30 , and found that I8o yards of channel had been sawn in twelve days, through ice 7 feet to 8 feet thick. The open water was then 17 . miles from the ship. As the canal cut had frozen over again in places, showing that the efforts were obviously futile, the men were sent back to the ship.

The relief ships arrived simultaneously at the edge of the ice on January 5. As they had closed but little on the Discovery by January ${ }^{1} 5$, all hands were employed in sledging and collecting the instruments. The ice began to weaken between the ships on January 20 , and broke rapidly towards the end of the month. The opening came within 8 miles of the ship in the early days of February. Its advance was slow, but it was increased by systematic blasting with dynamite. The crews of the relief ships were employed in making holes in the ice for this purpose. On February I2 a general break-up of the ice began, and the relief ships reached Hut Point amid much excitement. On the night of February I4 two heavy charges were exploded, and these placed the Discovery in open water.

On the morning of February I6 a heavy gale began. In the night the Terra. Nova succeeded in finding shelter to the south; but in the morning was driven north. The Discovery dragged her anchor and was forced ashore, remaining eight hours in a critical position. The ship eventually freed herself. On February 19, 75 tons of coal were obtained from the relief ships before a fresh gale drove the Discovery north. The ship was kept close in along the coast line, and in the morning parted company from the other ships at Cape Washington, with a clear sea to the north.

The Discovery skirted the pack to the east and north, losing sight of the Terra Nova during a gale on February 28. It proceeded west along parallel $69 \frac{1}{2}$ degrees of latitude, and on March 2 the Balleny and Russell Islands were

No. I797, VOL 69] found to be identical. It continued west to the 156 th meridian of longitude. The coast-line reported in this direction was found to be a mistake. No such land exists.

Auckland Island was reached on March 15. The Terra Nova and Morning rejoined the Discovery on March ig and 20 , after experiencing terrific weather and being compelled several times to heave to. The results of the expedition are eminently satisfactory.

UNIVERSITY EDUCATION IN SOUTH AFRICA. THERE was an especial appropriateness about the visit of Prof. Hele-Shaw, F.R.S., to the Cape of Good Hope University on the occasion of the degree day, on February 27, when he gave an address on the true function of a university and the directions in which university work in South Africa should be strengthened and developed. Prof. Hele-Shaw, it will be remembered, is in South Africa to organise technical education in the new colonies, and he is for the present acting as senior professor in charge of the department of mechanical and electrical engineering at the Transvaal Technical Institute. This institute will, it is hoped by the local authorities of the Transvaal, develop into a university, but the university authorities at the Cape of Good Hope naturally desire that the future shall see no undesirable competition and no overlapping between the university work of Cape Town and that of the Transvaal when the latter becomes fully organised. There is in other quarters the fear that in the work of instituting new universities an undue prominence may be given to the subjects of study of a more technical kind, and that the branches of knowledge usually associated with the inculcation of cultured ideas may be neglected. All these questions were discussed at length by Prof. HeleShaw.

The University of the Cape of Good Hope was incorporated by an Act of the Legislature in 1873 , and thereupon took the place of the Board of Public Examiners which had been similarly established in 1858 under the administration of the late Sir George Grey. In 1879 the late Queen Victoria granted a Royal Charter to the university declaring that the degrees conferred by the university are entitled to the same rank, precedence, and consideration as the degrees of any university in the United Kingdom. But, as was pointed out by the Cape Times of February 29, reporting the proceedings on degree day, as it is at present constituted the Cape University is almost exclusively an examining body. It is not, in the commonly accepted sense of the term, a teaching university, and however valuable it is for South Africa to number among its educational institutions a body which has the power to confer degrees, and thereby to set the seal of its authority upon the intellectual attainments of its graduates, this is not the highest of all advantages which a university can offer. This was the ideal at which the University of London formerly aimed but which it has been able to replace by a great teaching university which it is hoped will be soon worthy of the capital of the Empire. The need for a teaching university at Cape Town is beginning to be felt in South Africa-for a university at which the students will be brought into direct touch with the professors and lecturers, and not, as at present, an institution in which knowledge is tested wholly by examination papers. It is the influence and the teaching of the university as a whole which largely contribute to stimulate that affection for their college that is so distinguishing a feature of the great English and Scottish universities.

Prof. Hele-Shaw directed the attention of the authorities of the Cape of Good Hope University to the aspirations of those who are founding the Transvaal Trchnical Institute, and pointed out that their ultimate ideal is the foundation of a university for the Transvaal. Under existing conditions in South Africa, says the Cape Times, it may well be doubted if two university establishments could be effectively maintained without injury to the interests of one or the other. But if the country makes that progress in wealth and population and prosperity which it is hoped to see realised, the day when there will be ample room [1, a Transvaal university may not be very far removed. There need be no friction between those at work at Cape Town and Johannesburg respectively. 